\title{
Teste de tetrazólio para avaliação da qualidade fisiológica de sementes de melancia
}

\section{Tetrazolium test in the evaluation of watermelon physiological seed quality}

\author{
Marcela Carlota Nery ${ }^{*}$; Maria Laene Moreira de Carvalho ${ }^{2}$; Luciana Magda de Oliveira ${ }^{3}$
}

\section{Resumo}

O teste de tetrazólio é um dos métodos mais promissores para estimar, de forma rápida, a viabilidade e o vigor das sementes. Sua utilização em sementes de melancia requer cuidados na embebição e manuseio pela presença de camada mucilaginosa aderente ao tegumento. O objetivo do trabalho foi definir o tempo de embebição e do método de escarificação para retirada da mucilagem, no pré-condicionamento do teste de tetrazólio, sementes de diferentes cultivares de melancia. As sementes foram imersas em água a $30^{\circ} \mathrm{C}$ por 12 e 18 horas, e escarificadas em cal, areia fina e areia grossa. Após corte longitudinal na porção distal ao eixo embrionário, os tegumentos foram retirados e os embriões permaneceram em água por mais 2 horas a $30^{\circ} \mathrm{C}$ para remoção manual da membrana remanescente. Após definição do método ideal de précondicionamento, os embriões foram imersos em soluções de tetrazólio nas concentrações de $0,075 \%$; $0,5 \%$ e $1 \%$ por três e quatro horas a $30^{\circ} \mathrm{C}$. A imersão das sementes de melancia em água a $30^{\circ} \mathrm{C}$ por 12 horas, retirada da mucilagem com areia fina, corte longitudinal na porção distal ao eixo embrionário e remoção do tegumento, seguido da permanência dos embriões em água por 2 horas a $30^{\circ} \mathrm{C}$ para retirada manual da membrana interna e imersão na solução de tetrazólio a $0,075 \%$ por $4 \mathrm{~h}$ a $30^{\circ} \mathrm{C}$ são procedimentos adequados para avaliação da qualidade de sementes de melancia.

Palavras-chave: Citrullus lanatus, cucurbitáceas, viabilidade, vigor, pré-condicionamento

\begin{abstract}
The tetrazolium test is one of the most promising methods to estimate in a fast way viability and vigor of seeds. Its usage in watermelon seeds requires some care with the imbibition and handling due to presence of mucilaginous layer adherent to the tegument. The objective of this research work was to define the imbibition time and the method of scarification for removing the mucilage, during pre conditioning of the tetrazolium test in watermelon. Seeds from different watermellon cultivars were immersed in water at $30^{\circ} \mathrm{C}$ from 12 to 18 hours, and sloughed in cal, fine and thick sand. After longitudinal cut in the distal portion to the embryonic axis, the tegument was removed and embryos were kept in water for additonal 2 hours at $30^{\circ} \mathrm{C}$ for hand removal of the remaining membrane. After definition of the ideal pre - conditioning method, the embryos were immersed in tetrazolium solution in concentrations of $0,075 \% ; 0,5 \%$ and $1 \%$ for 3 and 4 hours at $30^{\circ} \mathrm{C}$. The immersion of watermelon seeds in water at $30^{\circ} \mathrm{C}$ for 12 hours, mucilage removal with fine sand, longitudinal cut in the distal portion to the embryonic axis, and removal of tegument, followed by the permanence of embryos in water for 2 hours at $30^{\circ} \mathrm{C}$ for the hand removal of the internal membrane and immersion in the tetrazolium solution at $0,075 \%$ for 4 hours at $30^{\circ} \mathrm{C}$ are adequate procedures for the evaluation of watermelon seed quality.
\end{abstract}

Key words: Citrullus lanatus, cucurbitaceaes, viability, vigor, pre-conditioning

1 Eng Agra ; MSc.; Doutoranda em Agronomia/Fitotencia da Universidade Federal de Lavras (UFLA). Rua Antonio Pereira, 81 Bairro Costa Pinto - Lavras-MG - Cep.:37200-000 E-mail: nery.marcela@gmail.com.

2 Eng. Agra ; Dra ; Prof ${ }^{a}$ Titular do Departamento de Agricultura da UFLA. Lavras, MG. E-mail: mlaenemc@ufla.br

3 Eng. Florestal.; Dra , Pós-doutoranda em Agronomia/Fitotecnia da UFLA. Lavras, MG. E-mail: lumagda@ufla.br

* Autor para correspondência 


\section{Introdução}

A melancia (Citrullus lanatus Thunb. Mansf.) é considerada uma das mais importantes olerícolas produzidas e comercializadas no Brasil, não somente pelas suas características nutricionais como também pelo seu valor comercial (CASTELLANE; CORTEZ, 1995).

É uma espécie propagada por sementes, que podem ser semeadas diretamente no campo ou em substratos para produção de mudas. A utilização de sementes de alta qualidade propicia não só uma emergência satisfatória como também o estabelecimento de plântulas vigorosas, que garantem o estande mais uniforme da cultura, a eliminação de operações de desbaste e a maturação uniforme das plantas (BHERING et al., 2003).

Nascimento (1991) cita a baixa qualidade das sementes de melancia como um dos principais problemas que afetam a cultura no Brasil. Estudando 23 lotes de sementes de melancia de 14 cultivares, o autor observou que três lotes apresentavam valores abaixo do padrão de germinação, que é de $75 \%$ para sementes de melancia certificadas, de acordo com os padrões do Ministério da Agricultura, Pecuária e Abastecimento.

O conhecimento da qualidade de um lote de sementes depende da disponibilidade de metodologias precisas, que levem a obtenção de resultados confiáveis (McDONALD, 1998). O teste de tetrazólio tem sido utilizado com sucesso nos programas de controle de qualidade de sementes, por ser um método rápido que estima a germinação potencial e o vigor de lotes de sementes (HAMPTON; COOLBEAR, 1990).

O teste de tetrazólio baseia-se na atividade das enzimas desidrogenases nos processos respiratórios dos tecidos. Durante a respiração, ocorre a liberação de íons hidrogênio, com os quais o sal 2,3,5 trifenil cloreto de tetrazólio reage formando uma substância de cor vermelha e insolúvel, denominada de formazam, nos tecidos vivos da semente (DELOUCHE et al., 1976).

A velocidade com que o sal de tetrazólio é absorvido pelos tecidos das sementes depende do número de barreiras físicas que este encontra (PINÃ RODRIGUES; SANTOS, 1988). Em muitas espécies, o pré-condicionamento das sementes se faz necessário visando a penetração da solução e a ativação do sistema respiratório (VIEIRA; VON PINHO, 1999).

Dentre os métodos de pré-condicionamento mais utilizados podem ser citados a punção, o corte e a retirada do tegumento; no entanto, algumas espécies apresentam camadas mucilaginosas que devem ser retiradas para que haja a absorção do sal de tetrazólio. Para sementes de Passiflora alata, Malavasi et al. (2001) recomendam o uso de liquidificador e a secagem à sombra por sete dias para retirada do arilo, comum a esta espécie. Enquanto que Pereira et al. (1997) observaram que a fricção em areia favorece a retirada da mucilagem de sementes da mesma espécie. Já Bhering, Dias e Barros (2005) removeram a mucilagem de sementes de melancia por meio da embebição em água e uso de cal virgem.

Além do pré-condicionamento, fatores como a concentração da solução ou mesmo o tempo de coloração na solução podem afetar a eficiência do teste na avaliação da qualidade das sementes $\mathrm{O}$ período necessário para o desenvolvimento da coloração adequada, segundo as Regras para Análise de Sementes (BRASIL, 1992) e Krzyzanowski, Vieira e França Neto (1999), varia com a espécie, situando entre 30 e 240 minutos.

Algumas pesquisas têm sido feitas tentando ajustar metodologias para o uso do teste de tetrazólio em várias espécies de cucurbitáceas, como abóbora (BARROS, 2002; DIAS et al., 2001) e abobrinha (BARROS, 2002), ou mesmo espécies que apresentam arilo como tomate (PANOBIANCO, 2000); no entanto, existem ainda deficiências na adequação da metodologia do teste de tetrazólio para a maioria das hortaliças (BARROS, 2002; SANTOS, 2003).

São variadas as indicações para a realização do teste de tetrazólio em sementes de melancia e outras cucurbitáceas são variadas. Delouche et al. (1976) recomendam para sementes de melancia a embebição em água entre $30^{\circ} \mathrm{C}$ e $35^{\circ} \mathrm{C}$ por uma hora 
para remover o tegumento e por mais uma a duas horas para remoção da membrana remanescente e concentração de $1 \%$ por uma ou duas horas no tetrazólio. As Regras para Análises de Sementes (BRASIL, 1992) recomendam, para sementes de cucurbitáceas, a embebição em água por 6-18 horas, seguida de corte longitudinal através da metade distal dos cotilédones, e embebição na solução de tetrazólio a $1 \%$ por 6-24 horas e posterior remoção do tegumento. Bhering et al. (2005) indicam a retirada do arilo e a imersão das sementes de melancia em água a $40^{\circ} \mathrm{C}$ por 60 minutos para retirada da membrana interna e concentração da solução de tetrazólio de $0,075 \%$ e a (ASSOCIATION OF OFFICIAL SEED ANALYSTS, 2005) prescreve o corte distal nos cotilédones para sementes de Citrullus, seguido de embebição em solução de tetrazólio a $0,1 \%$ overnight a $30-35^{\circ} \mathrm{C}$.

A presente pesquisa foi conduzida com o objetivo de definir o pré-condicionamento, concentração da solução e tempo de coloração nos procedimentos do teste de tetrazólio em sementes de melancia.

\section{Material e Métodos}

O experimento foi conduzido no Laboratório de Análise de Sementes da Universidade Federal de Lavras, MG. Foram utilizados as cultivares: Charleston Gray, Crimson Sweet, Esmeralda, Fairfax e o híbrido triplóide Tiffany.

Para determinação do teor de água, foi adotado o método estufa a $105^{\circ} \mathrm{C}+3{ }^{\circ} \mathrm{C}$ por 24 horas (BRASIL, 1992), com quatro repetições de quatro gramas de sementes acondicionadas em cápsulas de alumínio. Na realização do teste de germinação (G), quatro repetições de 50 sementes foram préembebidas por 6 horas semeadas em rolo de papel e postas para germinar a $25^{\circ} \mathrm{C}$, com luz constante. Foi computado o número de plântulas normais aos cinco (Primeira contagem - PC) e 14 dias (BRASIL, 1992). O Índice de velocidade de germinação (IVG) foi obtido segundo Maguire (1962) por meio dos resultados das avaliações do teste de germinação, realizadas as contagens diariamente. $\mathrm{O}$ teste de
Emergência em condições controladas (ECC) foi conduzido em substrato terra e areia na proporção $1: 2$ e $60 \%$ da capacidade de campo, em bandejas plásticas mantidas em sala de crescimento a $25^{\circ} \mathrm{C}$ e 8 horas de luz. Foi avaliado o número de plantas emersas aos 5 (Estande inicial - EI) e 14 dias (ECC). O Índice de velocidade de emergência (IVE) foi realizado com os dados obtidos no teste de emergência, e calculado segundo Maguire (1962). As plântulas obtidas no teste de emergência foram cortadas rente ao solo, pesadas e mantidas em estufa de circulação forçada de ar a $60^{\circ} \mathrm{C}$, até peso constante para a obtenção do Massa seca de parte aérea de plântulas (MS).

Para o teste de tetrazólio (TZ) as sementes das cinco cultivares foram embebidas diretamente em água por 12 e 18 horas a $30^{\circ} \mathrm{C}$. Para auxiliar na remoção da mucilagem, as sementes foram escarificadas em cal, areia fina e areia grossa. Em seguida, foi realizado corte longitudinal na porção distal ao eixo embrionário, os tegumentos foram retirados e os embriões permaneceram em água por mais 2 horas a $30^{\circ} \mathrm{C}$ para remoção manual da membrana interna. Os embriões foram imersos em solução de tetrazólio a $0,075 \% ; 0,5 \%$ e $1 \%$ em recipientes plásticos e mantidos por $3 \mathrm{e} 4$ horas em $\mathrm{BOD}$ a $30^{\circ} \mathrm{C}$, no escuro, para coloração. Utilizando quatro repetições de 50 sementes para cada tratamento.

Para avaliação, os embriões foram seccionados no sentido longitudinal, e separados de acordo com a viabilidade em viáveis ( $50 \%$ ou mais do embrião, eixo embrionário e região de translocação intactas e coloridos) e inviáveis. Os embriões foram também classificados de acordo com o nível de vigor em notas 1 (viáveis e vigorosos), 2 (viáveis e não vigorosos) e 3 (inviáveis).

$\mathrm{O}$ experimento foi realizado em delineamento inteiramente casualizado, com quatro repetições de 50 sementes. Os dados obtidos em porcentagem foram transformados em arco sen Öx/100, comparados pelo teste de Tukey a $5 \%$ de probabilidade. Foram calculados os coeficientes de correlação simples de Pearson (r) entre os testes utilizados para avaliação da qualidade de sementes de melancia e o teste de tetrazólio, exceto para os resultados obtidos na 
determinação da massa seca de parte aérea de plântulas. A significância dos valores de $r$ foi determinada a $1 \%$ de probabilidade, por meio do programa Sanest (ZONTA; MACHADO, 1996).

\section{Resultados e Discussão}

A umidade das sementes das diferentes cultivares variou de $7 \%$ a $8 \%$, o que indica uniformidade dos lotes em relação a esse fator, que pode interferir no período de pré-condicionamento.

O percentual de germinação variou entre as cultivares, destacando-se a cultivar Esmeralda em relação às cultivares Fairfax, Crimson Sweet e Tiffany. O percentual de germinação de cultivar Tiffany, 39\%, foi estatisticamente inferior as demais cultivares (Tabela 1).

Com relação aos dados da primeira contagem da germinação e índice de velocidade de germinação observa-se, em ambos os testes, a superioridade das cultivares Esmeralda e Charleston Gray em relação às outras cultivares.
Ainda na Tabela 1 podem ser visualizados os dados relacionados ao vigor das diferentes cultivares, avaliados pelos testes estande inicial, emergência em condições controladas e IVE. As cultivares Esmeralda, Charleston Gray, Crimson Sweet e Fairfax não diferiram entre si e apresentaram qualidade superior em relação ao híbrido triplóide Tiffany. Segundo Souza, Queiroz e Dias (1999) a baixa qualidade de sementes de híbridos triplóides em relação aos diplóides pode ocorrer, visto que as mesmas levam mais tempo para germinar e têm problemas de má-formação de embrião pela alteração cromossômica necessária para evitar a formação das sementes e a restauração desses genes (GRANGEM et al., 2003).

Pelos resultados da determinação da massa seca da parte aérea de plântulas, não foram observadas diferenças entre as cultivares. Alguns autores consideram que essa determinação pode não refletir o vigor dos lotes uma vez que a emergência resulta de uma interação complexa da qualidade da semente com o ambiente de semeadura, que afeta o desenvolvimento da plântula (BASRA,1995; PERRY, 1984).

Tabela 1. Valores médios (\%) de germinação $(\mathrm{G})$, primeira contagem da germinação (PC), índice de velocidade de germinação (IVG), estande inicial (EI), emergência em condições controladas (ECC), índice de velocidade de emergência (IVE) e peso seco das plântulas (PS) de cinco cultivares de melancia.

\begin{tabular}{lccccccc}
\hline & \multicolumn{7}{c}{ Testes* $^{*}$} \\
\hline Cultivares & G & PC & IVG & EI & ECC & IVE & PS \\
Esmeralda & $99 \mathrm{a}$ & $50 \mathrm{a}$ & $49,12 \mathrm{a}$ & $38 \mathrm{a}$ & $93 \mathrm{a}$ & $10,83 \mathrm{a}$ & $1,59 \mathrm{a}$ \\
C. Gray & $95 \mathrm{ab}$ & $47 \mathrm{a}$ & $34,41 \mathrm{~b}$ & $44 \mathrm{a}$ & $93 \mathrm{a}$ & $11,65 \mathrm{a}$ & $3,48 \mathrm{a}$ \\
Fairfax & $89 \mathrm{~b}$ & $43 \mathrm{~b}$ & $24,46 \mathrm{c}$ & $42 \mathrm{a}$ & $92 \mathrm{a}$ & $10,59 \mathrm{a}$ & $1,20 \mathrm{a}$ \\
C..Sweet & $91 \mathrm{~b}$ & $44 \mathrm{~b}$ & $21,72 \mathrm{c}$ & $40 \mathrm{a}$ & $94 \mathrm{a}$ & $10,51 \mathrm{a}$ & $1,08 \mathrm{a}$ \\
Tiffany & $39 \mathrm{c}$ & $4 \mathrm{c}$ & $2,24 \mathrm{~d}$ & $4 \mathrm{~b}$ & $28 \mathrm{~b}$ & $2,49 \mathrm{~b}$ & $1,46 \mathrm{a}$ \\
CV $(\%)$ & 7,82 & 2,89 & 9,23 & 15,57 & 7,11 & 6,58 & 53,32 \\
\hline
\end{tabular}

*As médias seguidas da mesma letra minúscula nas colunas não diferem entre si pelo de teste Tukey, a 5\% de probabilidade.

Na avaliação pelo teste de tetrazólio foi observado que a embebição das sementes por 18 horas em água induziu a germinação das sementes, dificultando a análise do teste de tetrazólio. O pré-condicionamento das sementes de melancia em água por 12 horas propiciou a formação de um espaço entre o tegumento e o embrião, facilitando assim o corte longitudinal distal ao eixo embrionário.

O uso de areia fina foi o método de précondicionamento mais adequado para a remoção da mucilagem das sementes comparado com o uso de cal e areia grossa. Resultados semelhantes em 
relação à eficiência do uso de areia para retirada da mucilagem foram descritos por Pereira e Dias (2000) em sementes de Passiflora alata. Apesar de Bhering, Dias e Barros (2005) recomendarem a utilização da cal para remoção da mucilagem de sementes de melancia. Foi observado, neste experimento, que tanto areia grossa como cal levaram a formação de um aglomerado de sementes, que dificultou o manuseio e a individualização das sementes para o corte.

Com base na coloração dos tecidos os embriões de melancia foram classificados em três categorias, viáveis, vigorosos e inviáveis, conforme Figura 1.

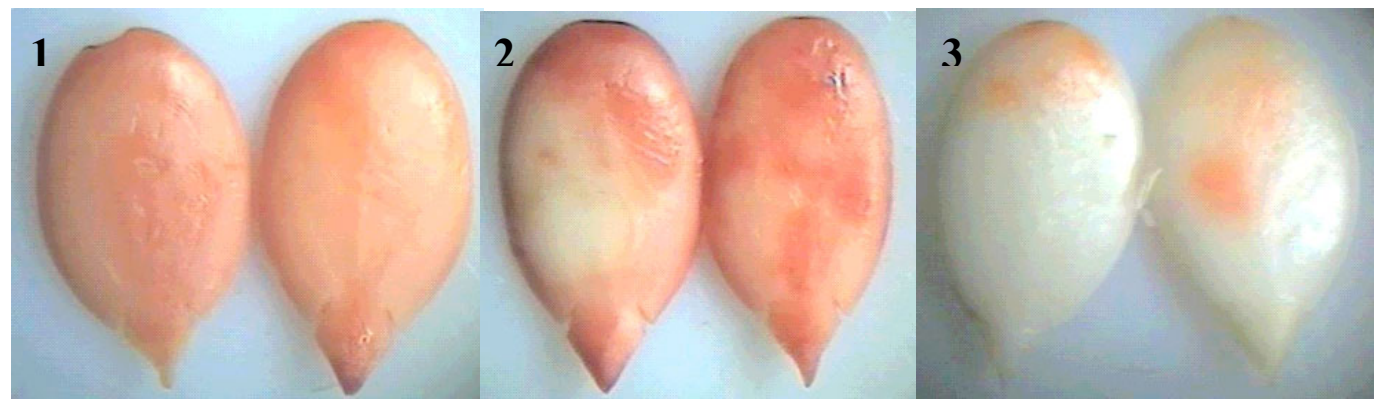

Figura 1. Categorias de embriões de melancia submetidos ao teste de tetrazólio: Viáveis e vigorosos: 1 - embrião com coloração rosa ou mais escura e tecidos com aspecto normal e firme; Viáveis e não vigorosos: 2 - menos de $50 \%$ dos cotilédones descoloridos, não afetando a região de ligação com o eixo embrionário; Inviáveis: 3 - parte do eixo embrionário ou região de translocação de reservas descoloridas ou embrião completamente descolorido.

Com base nessa classificação, o resultado de viabilidade obtido para as diferentes cultivares variou de 31 a $100 \%$ de viabilidade. A resposta ao teste de tetrazólio depende da concentração e tempo de solução, sendo que a concentração de $0,075 \%$ por 3 horas não permitiu a diferenciação de lotes de sementes de melancia, já nas concentrações de $0,075 \%$ por 4 horas e $1 \%$ por 3 horas houve a separação dos lotes em três níveis de qualidade (Tabela 2). A $0,075 \%$ por 4 horas os resultados de viabilidade se assemelham à classificação de lotes obtida pelo teste de germinação (Tabela 1), distinguindo a cultivar Esmeralda de qualidade superior, as cultivares Charleston Gray, Fairfax e Crimson Sweet com tendência de resultados intermediários e o híbrido Tiffany com resultados inferiores de viabilidade.

Tabela 2. Valores médios (\%) de viabilidade de sementes de melancia de diferentes cultivares avaliada pelo teste de tetrazólio.

\begin{tabular}{lcccccc}
\hline \multirow{2}{*}{ Cultivares } & \multicolumn{6}{c}{ Tratamentos* } \\
\cline { 2 - 7 } & \multicolumn{2}{c}{$0,075 \%$} & \multicolumn{2}{c}{$0,5 \%$} & \multicolumn{3}{c}{$1 \%$} \\
\cline { 2 - 7 } & $9 \mathrm{~h}$ & $4 \mathrm{~h}$ & $3 \mathrm{~h}$ & $4 \mathrm{~h}$ & $9 \mathrm{~h}$ & $4 \mathrm{~h}$ \\
\hline Esmeralda & $98 \mathrm{a}$ & $100 \mathrm{a}$ & $100 \mathrm{a}$ & $99 \mathrm{a}$ & $99 \mathrm{ab}$ & $100 \mathrm{a}$ \\
Charleston Gray & $99 \mathrm{a}$ & $99 \mathrm{ab}$ & $98 \mathrm{a}$ & $93 \mathrm{ab}$ & $100 \mathrm{a}$ & $99 \mathrm{a}$ \\
Fairfax & $97 \mathrm{a}$ & $94 \mathrm{~b}$ & $98 \mathrm{a}$ & $88 \mathrm{~b}$ & $91 \mathrm{bc}$ & $98 \mathrm{a}$ \\
Crimson Sweet & $98 \mathrm{a}$ & $99 \mathrm{ab}$ & $97 \mathrm{a}$ & $96 \mathrm{ab}$ & $99 \mathrm{ab}$ & $100 \mathrm{a}$ \\
Tiffany & $82 \mathrm{a}$ & $79 \mathrm{c}$ & $31 \mathrm{~b}$ & $86 \mathrm{~b}$ & $77 \mathrm{c}$ & $83 \mathrm{~b}$ \\
CV (\%) & 12,37 & 7,25 & 27,21 & 9,05 & 7,47 & 8,59 \\
\hline
\end{tabular}

*As médias dentro de cada coluna seguidas da mesma letra não diferem entre si pelo de teste Tukey, a 5\% de probabilidade. 
Tabela 3. Valores médios (\%) de vigor de sementes das cultivares de melancia avaliado pelo teste de tetrazólio.

\begin{tabular}{|c|c|c|c|c|c|c|}
\hline \multirow{3}{*}{ Cultivares } & \multicolumn{6}{|c|}{ Tratamentos* } \\
\hline & \multicolumn{2}{|c|}{$0,075 \%$} & \multicolumn{2}{|c|}{$0,5 \%$} & \multicolumn{2}{|c|}{$1 \%$} \\
\hline & $3 \mathrm{~h}$ & $4 \mathrm{~h}$ & $3 \mathrm{~h}$ & $4 \mathrm{~h}$ & $3 \mathrm{~h}$ & $4 \mathrm{~h}$ \\
\hline Esmeralda & 98 a & $97 \mathrm{a}$ & 99 a & 99 a & $94 \mathrm{a}$ & $99 \mathrm{ab}$ \\
\hline Charleston Gray & 98 a & $98 \mathrm{a}$ & $98 \mathrm{a}$ & $93 a b$ & 99 a & $99 \mathrm{ab}$ \\
\hline Fairfax & $94 \mathrm{ab}$ & $92 \mathrm{ab}$ & $95 \mathrm{ab}$ & $84 \mathrm{~b}$ & $88 \mathrm{a}$ & $93 \mathrm{~b}$ \\
\hline Crimson Sweet & $97 \mathrm{ab}$ & 98 a & 98 a & $97 \mathrm{ab}$ & $97 \mathrm{a}$ & $100 \mathrm{a}$ \\
\hline Tiffany & $58 \mathrm{~b}$ & $78 \mathrm{~b}$ & $31 \mathrm{~b}$ & $84 \mathrm{~b}$ & $96 \mathrm{a}$ & $61 \mathrm{c}$ \\
\hline CV (\%) & 20,00 & 7,96 & 28,27 & 8,63 & 10,04 & 7,70 \\
\hline
\end{tabular}

*As médias dentro de cada coluna seguidas da mesma letra não diferem entre si pelo de teste Tukey, a $5 \%$ de probabilidade.

Pelas Tabelas 2 e 3 pode-se observar que a concentração de $0,075 \%$ por 4 horas separou os lotes em melhor e pior qualidade, tanto em nível de vigor quanto viabilidade; além disso, nesta concentração foram observados um dos menores coeficientes de variação. O coeficiente de variação, segundo Gomes (1991), mede a variação entre repetições.

Analisando as Tabelas 4 e 5, foi observado que os resultados de todos os tratamentos se correlacionam com os resultados da maioria dos testes utilizados, ou seja, foram eficientes para distinção da qualidade das cultivares de sementes de melancia, exceto a $0,075 \%$ por 3 horas e $0,5 \%$ por 4 horas na viabilidade e $0,5 \%$ por 4 horas e $1 \%$ por 3 horas na avaliação do vigor, que não apresentaram correlação com a emergência em campo ou distinção dos lotes. Para os demais tempos e concentrações da solução existe a possibilidade de utilização do teste de tetrazólio.

Tabela 4. Coeficientes de correlação simples (r) entre os dados dos testes utilizados para avaliação da qualidade fisiológica e viabilidade obtidos no teste de tetrazólio de sementes de melancia.

\begin{tabular}{lcccccc}
\hline & \multicolumn{7}{c}{ Tratamentos } \\
\cline { 2 - 7 } & \multicolumn{2}{c}{$0,075 \%$} & \multicolumn{2}{c}{$0,5 \%$} & \multicolumn{2}{c}{$1 \%$} \\
\hline Testes & $3 \mathrm{~h}$ & $4 \mathrm{~h}$ & $\mathrm{~h}$ & $4 \mathrm{~h}$ & $\mathrm{~h}$ & $4 \mathrm{~h}$ \\
PC & $0,34 \mathrm{~ns}$ & $0,60 \mathrm{~ns}$ & $0,62 \mathrm{~ns}$ & $0,57 \mathrm{~ns}$ & $0,69 \mathrm{~ns}$ & $0,47 \mathrm{~ns}$ \\
TG & $0,65 \mathrm{~ns}$ & $0,81 *$ & $0,76 *$ & $0,54 \mathrm{~ns}$ & $0,83 *$ & $0,81 *$ \\
IVG & $0,49 \mathrm{~ns}$ & $0,69 \mathrm{~ns}$ & $0,59 \mathrm{~ns}$ & $0,60 \mathrm{~ns}$ & $0,68 \mathrm{~ns}$ & $0,61 \mathrm{~ns}$ \\
EI & $0,60 \mathrm{~ns}$ & $0,72 *$ & $0,76 *$ & $0,39 \mathrm{~ns}$ & $0,77 *$ & $0,71 *$ \\
ECC & $0,65 \mathrm{~ns}$ & $0,81 *$ & $0,85 *$ & $0,46 \mathrm{~ns}$ & $0,85 *$ & $0,78 *$ \\
IVE & $0,63 \mathrm{~ns}$ & $0,76 *$ & $0,80 *$ & $0,41 \mathrm{~ns}$ & $0,83 *$ & $0,74 *$ \\
\hline
\end{tabular}

* - significativo pelo teste de correlação simples (r) a 5\% de probabilidade.

ns - não significativo pelo teste de correlação simples (r) a 5\% de probabilidade. 
Tabela 5. Coeficientes de correlação simples (r) entre os dados dos testes utilizados para avaliação da qualidade fisiológica e vigor obtidos no teste de tetrazólio de sementes de melancia.

\begin{tabular}{|c|c|c|c|c|c|c|}
\hline \multirow[b]{3}{*}{ Testes } & \multicolumn{6}{|c|}{ Tratamentos } \\
\hline & \multicolumn{2}{|c|}{$0,075 \%$} & \multicolumn{2}{|c|}{$0,5 \%$} & \multicolumn{2}{|c|}{$1 \%$} \\
\hline & $3 \mathrm{~h}$ & $4 \mathrm{~h}$ & $3 \mathrm{~h}$ & $4 \mathrm{~h}$ & $3 \mathrm{~h}$ & $4 \mathrm{~h}$ \\
\hline $\mathrm{PC}$ & $0,45 \mathrm{~ns}$ & $0,49 \mathrm{~ns}$ & $0,50 \mathrm{~ns}$ & $0,65 \mathrm{~ns}$ & $0,22 \mathrm{~ns}$ & $0,56 \mathrm{~ns}$ \\
\hline $\mathrm{TG}$ & $0,69 \mathrm{~ns}$ & $0,84 *$ & $0,69 \mathrm{~ns}$ & $0,63 \mathrm{~ns}$ & $0,13 \mathrm{~ns}$ & $0,87 *$ \\
\hline IVG & $0,58 \mathrm{~ns}$ & $0,65 \mathrm{~ns}$ & $0,59 \mathrm{~ns}$ & $0,64 \mathrm{~ns}$ & $0,15 \mathrm{~ns}$ & $0,61 \mathrm{~ns}$ \\
\hline EI & $0,74 *$ & $0,73 *$ & $0,75 *$ & $0,41 \mathrm{~ns}$ & $0,17 \mathrm{~ns}$ & $0,82 *$ \\
\hline $\mathrm{ECC}$ & $0,84 *$ & $0,73 *$ & $0,85 *$ & $0,48 \mathrm{~ns}$ & $0,22 \mathrm{~ns}$ & 0,80 * \\
\hline IVE & $0,78 *$ & $0,70 *$ & $0,79 *$ & $0,46 \mathrm{~ns}$ & $0,23 \mathrm{~ns}$ & $0,85 *$ \\
\hline
\end{tabular}

* - significativo pelo teste de correlação simples (r) a $5 \%$ de probabilidade.

ns - não significativo pelo teste de correlação simples (r) a 5\% de probabilidade.

Segundo Marcos Filho (1994), a escolha de metodologia adequada para o emprego do teste de tetrazólio em sementes se baseia na facilidade para diferenciação de tecidos viáveis e inviáveis, no estudo econômico e na capacidade de diferenciar lotes de qualidade fisiológica distintas. Desta forma, a concentração de $0,075 \%$ por 4 horas atende os requisitos de economia e se presta para diferenciação de lotes em relação à viabilidade e vigor.

A concentração de $0,075 \%$ da solução de tetrazólio foi indicada como ideal para outras espécies; porém, por tempos de coloração diferenciados como abóbora e abobrinha, por 60 minutos a $40^{\circ} \mathrm{C}$ (BARROS et al., 2005) e Passiflora alata, por cinco e três horas (MALAVASI et al., 2001).

\section{Conclusão}

Em seqüência, a pré-imersão de sementes de melancia em água a $30^{\circ} \mathrm{C}$ por 12 horas, retirada da mucilagem com areia fina, corte longitudinal na porção distal ao eixo embrionário e remoção do tegumento, seguido da permanência dos embriões em água por 2 horas a $30^{\circ} \mathrm{C}$ para retirada manual da membrana interna e imersão dos embriões na solução de tetrazólio a $0,075 \%$ por $4 \mathrm{~h}$ a $30^{\circ} \mathrm{C}$ são procedimentos adequados para avaliação da qualidade de sementes de melancia, pelo teste de tetrazólio.

\section{Agradecimentos}

Agradecemos ao Conselho Nacional de Desenvolvimento Científico e Tecnológico - CNPq pela bolsa de iniciação científica concedida a primeira autora.

\section{Referências}

ASSOCIATION OF OFFICIAL SEED ANALYSTS - AOSA. Tetrazolium Testing Handbook: contribution n.29. Suite A, Las Cruces, AOSA, 2005.

BARROS, D. I. Teste de tetrazólio para avaliação da qualidade fisiológica de sementes de abóbora e abobrinha. 2002. Dissertação (Mestrado em Fitotecnia) Universidade Federal de Viçosa, Viçosa.

BARROS, D. I.; DIAS, D. C. F. S; BHERING, M. C.; DIAS, L. A. S.; ARAÚJO, E. F. Uso do t este de tetrazólio para avaliação da qualidade fisiológica de sementes de abobrinha. Revista Brasileira de Sementes, Londrina, v.27, n.2, p.165-171, 2005.

BASRA, A. S. Seed quality: basic mechanisms and agriculture implications. New York: Food Products Press, 1995. p.173-207.

BHERING, M. C.; DIAS, D. C. F. S.; BARROS, D. I. Adequação da metodologia do teste de tetrazólio para avaliação da qualidade fisiológica de sementes de melancia. Revista Brasileira de Sementes, Londrina, v.27, n.1, p.176-182, 2005.

BHERING, M. C.; DIAS, D. C. F. S.; BARROS, D. I.; TOKUHISA, D. Avaliação do vigor de sementes de 
melancia (Citrullus lunatus Schrad.) pelo teste de envelhecimento acelerado. Revista Brasileira de Sementes, Londrina, v.25, n.2, p.1-6, 2003.

BRASIL. Ministério da Agricultura e da Reforma Agrária. Regra para análise de sementes. Brasília: SNPA/DNPV/ CLAV, 1992.

CASTELlane, P. D.; CORTEZ, G. E. P. A cultura da melancia. Jaboticabal: FUNEP, 1995.

DELOUCHE, J. C.; STILL, T. W.; RASPET, M.; LIENHARD; M. O teste de tetrazólio para viabilidade da semente. Brasília: AGIPLAN, 1976.

DIAS, D. C. F. S.; BARROS, D. I.; BHERING, M. C.; ARAÚJO, E. F.; DIAS, L. A. S. Teste de tetrazólio em sementes de abóbora. Informativo Abrates, Londrina, v.11, n.2, p.124, 2001.

GRANGEM, S.; LESKOVAR, D.; PIKE, L. M.; COBB, B. G. Seed coat structure and oxygen enhanced environments affect germination of triploid watermelon. Journal of the American Society for Horticultural Science, Alexandria, v.128, n.2, p.253-259, 2003.

HAMPTON, J. G.; COOLBEAR, P. O. Potential versus actual seed performance $3 / 4$ can vigour testing provide an answer? Seed Science and Technology, Zürich, v.18, n.2, p.215-228, 1990.

KRZYZANOWSKI, F. C.; VIEIRA, R. D.; FRANÇA-NETO, J. B. Vigor de sementes: conceitos e testes. Londrina: ABRATES, 1999. cap.8.1, p.1-13.

MAGUIRE, J. D. Speed of germination-aid in selection and evaluation for seedling emergence and vigor. Crop Science, Madison, v.1, n.1, p.176-177, 1962.

MALAVASI, M. M.; FOGAÇA, C. A.; FOGAÇA, L. A.; FERREIRA, G. Preparo e coloração de sementes de maracujá- doce (Passiflora alata Dryander) para avaliação da viabilidade através do teste de tetrazólio. Revista Brasileira de Fruticultura, Jaboticabal, v.23, n.1, p.126129, abr., 2001.

MARCOS FILHO, J. Utilização de testes de vigor em programas de controle de qualidade de sementes. Informativo ABRATES, Londrina, v.4, n.2, p.3-35, 1994.

McDONALD, M. B. Improving our understanding of vegetable and flower seed quality. Seed Technology, Springfield, v.20, n.2, p.121-124, 1998.

NASCIMENTO, W. M. Avaliação da qualidade de sementes de melancia. Horticultura Brasileira, Botucatu, v.9, n.1, p.26, 1991 .
PANOBIANCO, M. Avaliação do potencial fisiológico de sementes de tomate. 2000. Dissertação (Doutorado em Fitotecnia) - Escola Superior de Agricultura Luiz de Queiroz, Universidade de São Paulo, Piracicaba.

PEREIRA, K. J. C.; DIAS, D. C. F. Germinação e vigor de sementes de maracujá-amarelo (Passiflora edulis Sims. f. flavicarpa Deg.) submetidas a diferentes métodos de remoção da mucilagem. Revista Brasileira de Sementes, Londrina, v.22, n.1, p.288-291, 2000.

PEREIRA, S. B.; VASCONCELLOS, M. A. S; ROSSETO, C. A. V.; LOPES, H. M. Efeitos da remoção do arilo e da superação da dormência na emissão da raiz primária de sementes de maracujá doce (Passiflora alata Dryand) Assifloraceae. Informativo ABRATES, Curitiba, v.7, n.1, p.104, 1997.

PERRY, D. A. Factors influencing the establishment of cereal crops. Aspects of Applied Biology, v.7, p.65-83, p.6583,1984

GOMES, F. P. O índice de variação, um substituto vantajoso do coeficiente de variação. Piracicaba: IPEF, 1991. (Circular técnica, n.178).

PIÑA RODRIGUES, F. C. M.; SANTOS, N. R. F. Teste de tetrazólio. In: PIÑA-RODRIGUES, F. C. M. Manual de análise de sementes florestais. Campinas: Fundação Cargill, 1988.

SANTOS, M. A. O. Avaliação do potencial fisiológico de sementes de tomate através do teste de tetrazólio. 2003. Dissertação (Mestrado em Fitotecnia) - Escola Superior de Agricultura Luiz de Queiroz, Universidade de São Paulo, Piracicaba.

SOUZA, F. F.; QUEIROZ, M. A.; DIAS, R. C. S. Avaliação preliminar de híbridos experimentais de melancia sem sementes. Horticultura Brasileira, Brasília, v.17, n.3, p.330, nov. 1999.

VIEIRA, M. G. G. C .; PINHO, E. V. R. V. Metodologia do teste de tetrazólio em sementes de algodão. In: KRZYANOWSKI, F. C.;VIEIRA, R. D.; FRANÇA NETO, J. B. (Ed.). Vigor de sementes: conceitos e testes. Londrina: ABRATES,1999. cap.8, p.8.1-8.13.

ZONTA, E. P.; MACHADO, A. A. Sistema de análise estatística para microcomputadores. Pelotas: Instituto de Física e Matemática, Universidade Federal de Pelotas, 1996. 